\title{
Youths' Posting Practices on Social Media for Digital Storytelling
}

\author{
María-José Rubio-Hurtado ${ }^{1} \oplus$, Marc Fuertes-Alpiste ${ }^{2} \odot$, Francesc Martínez-Olmo ${ }^{1} \odot$ and Jordi \\ Quintana ${ }^{3}(0)$
}

\author{
${ }^{1}$ Departament de Mètodes d'Investigació i Diagnòstic en Educació, Universitat de Barcelona, Spain \\ ${ }^{2}$ Departament de Teoria i Història de l'Educació, Universitat de Barcelona, Spain \\ ${ }^{3}$ Departament de Didàctica i Organització Educativa, Universitat de Barcelona, Spain
}

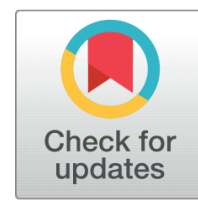

Received 2021-02-19

Revised 2021-03-04

Accepted 2021-05-27

Published 2022-01-15

Corresponding Author

Francesc Martínez-Olmo,

fmartinezo@ub.edu

Passeig Vall d'Hebron, 171 Edifici Llevant 08035, Barcelona, Spain

DOI https://doi.org/10.7821/

naer.2022.1.729

Pages: 97-113

Funding: Ministry of Economy and Competitiveness, Spain \& European Regional Development Fund (Award:EDU2016-76726-P)

Distributed under

CC BY-NC 4.0

Copyright: ( ) The Author(s)

\section{OPEN ACCESS}

\section{ABSTRACT}

Most young people spend time online every day in order to access social networks, where not only do they consume, but also produce content. The posting of content ends up reflecting a personal story in which young people recognize themselves. This posting practice requires competences that can be developed in digital literacy-related educational activities. Our research is aimed at understanding the posting habits of young people with the goal of integrating these practices in formal educational contexts. For this purpose, we have qualitatively analyzed the interviews of 21 young people. The results show different posting habits, as well as the motivating factors, perceptions and types of content posted by young people on social networks. An interpretative analysis of the results shows the possibilities of working on the storytelling experiences of young people on social networks from the perspective of the Personal Digital Storytelling educational methodology.

Keywords SOCIAL NETWORK, DIGITAL LITERACY, DIGITAL STORYTELLING, YOUTH, TEENAGER

\section{INTRODUCTION}

Adolescents and youths dedicate a significant amount of their time posting contents on digital social media and social networking sites (AIMC, 2021a, 2021b; IAB \& Elogia, 2020). This content, which is normally shaped as stories, is becoming part of the new participation ecology (Jenkins, Purushotma, Weigel, Clinton, \& Robison, 2009). The traditional consumer of media is now an active agent that increasingly creates, remixes and shares new content on social media networks (Jenkins, Ito, \& Boyd, 2015) that act as a mediating element of youths' everyday activities, their corporal and behavioral expressions and their peer relationships. They serve as "technologies of the self" (Davis, 2004; Rodríguez-Illera, 2014), which are a part of one's own way of acting, of interacting with others and of being.

Additionally, the educational field seeks to make connections between youngsters' digital posting practices and the educational strategies that support them (Dennen, Choi, 
\& Word, 2020), but also to empower them in the critical use of media (Mirra, Morrell, \& Filipiak, 2018). Narrative-based methodologies such as digital storytelling, can act as timely formative strategies, allowing teenagers and youths to construct their own discourse through different media. Their formative potential is concerned with fostering reflection processes of identity and personal experiences and on learning processes (Gregori-Signes \& Corachán, 2014).

However, to what extent can we make a connection between methodologies such as digital storytelling and youths' narrative practices on social networks? In this sense, this study presents a double aim:

- To understand youths' narrative practices on social networking sites: which ones they use, and with what purpose, what kind of content they publish, what their motivating factors and perceptions are and what posting habits they have.

- Based on the previous aim, we want to obtain keys for the integration of these practices into formal education contexts (to ascertain if they can be the groundwork for the digital storytelling methodology and to identify how they can help enhance these practices).

There are many systematic reviews that analyze the integration of social media into educational contexts (Dennen et al., 2020; Vanwynsberghe \& Verdegem, 2013) or how these have been integrated into writing practices in formal education (Galvin \& Greenhow, 2020). In them, we find several practices with social media for teaching and learning in the classroom, but none has identified studies on how posting stories on digital social media can have an influence on the creation of narratives or traditional digital storytelling. Moreover, most of these studies only provide data without analyzing the youths' symbolic and practical experience of media (Martínez \& Hernández, 2017; Winocur, 2007). However, the main focus of this study is on how adolescents and youths, who are used to publishing digital narratives, could benefit from methodologies such as digital storytelling. This methodology could channel their digital practices from a formal educational setting, helping them enhance their experience as creators of digital contents, project their identities on social media and also improve their digital and media literacy skills.

\section{LITERATURE REVIEW}

\subsection{Use of Social Media in the Participation Ecology}

The emergence of the Social Web or Web 2.0, and the use of social media and new mobile devices (tablets and smartphones) has fostered a new participation ecology (Jenkins et al., 2009). This new ecology enables any individual to form part of an audience in a participative and active manner when creating, sharing and interacting with content (Livingstone, 2004). When it comes to discussing young people, it is crucial to consider their role not only as consumers but also as producers and creators of content. The term "prosumer" was coined by Toffler (1980) to refer to a person who simultaneously performs two roles, that of 
a producer and that of a consumer, which had traditionally been differentiated. This concept has evolved towards that of the "produser" (a combination of producer and user), a term coined by Bruns (2008) and updated by Guerrero, Masanet, and Scolari (2018).

Indeed, participation has become an everyday practice (Abercrombie \& Longhurst, 1998). According to the same authors, there is an increasingly direct relationship between practices on social networks and the idea of the diffused audience, a combination of narcissism and spectacle. This idea is based on the fact that media products and networks are part of our daily lives and, as such, all the events of our daily lives are worthy of being recorded and shared. In turn, individuals always act in order to be observed; they are the center of attention in all the events of their daily lives, in terms of where they are, what they are doing and who they are with.

\subsection{Content of the Posts, Motivating Factors and Perceptions}

Young people see digital spaces as places of communication and expression. They consider the shift from the private to the public sphere in everything they post or share (De Ridder \& Van Bauwel, 2015; Sánchez et al., 2015). Transitioning from the private to the public sphere is a difficult act for the poster, and a revelation for their audience (Rodríguez-Illera, 2014). It may involve something more than mere expression in the case of young people; storytelling and self-promotional elements may come into play. In this sense, Brandtzaeg and Chaparro-Domínguez (2020) studied how self-presentation of young people in social media evolves across contexts, which is how they manage what they show in terms of their image and, thus, their identity. Self-presentation in social media is related to impression management and identity and to controlling how others perceive them on these platforms.

In the act of telling a personal story, an individual recognizes themself, and in this respect the self represents the awareness of what the individual is or believes themself to be in a certain moment or how they want to be perceived (Herreros, 2012).

For McAdams and Josselson (2006), these self-awareness processes are related to the concept of narrative identity, which is a story that gives meaning to life itself (Ricoeur, 1996), and to making sense of the world and of one's experience, functioning as a key structure of one's mind (Bruner, 2006; Lévi-Strauss, 1966). Personal or autobiographical stories organize a life and give it a certain sense of coherence, putting different aspects of the self in the same place.

The act of telling a story is a way of establishing meanings that are often related to one's emotional side (Egan, 1986). Moreover, by viewing other personal stories, one can acquire knowledge and feel emotions (Herreros, 2019). Thus, as seen in Bai et al's (2019) systematic review on the use of emojis, young people include them to express emotions, enhancing the emotional expression of what is being posted (Brandtzaeg \& Chaparro-Domínguez, 2020) or even functioning as a stand-alone language with its own meaning (Shah \& Tewari, 2021).

However, these stories are different depending on the age of the storyteller. While older people can reflect on past events, children and teenagers do not yet have this perspective; they are rather gathering elements in order to define and create their own narrative identity, thinking about their place in the world through stories which define them and which they 
will shape over the course of their adult lives (Mcadams, 1996). Schater (1999) explains that, over time, we codify and store new experiences that influence our capacity to remember and perceive previous ones. In a story of one's own experience, facts are interpreted and memories of the past end up being influenced by how we perceive ourselves to be in the present (Schater, 2003).

In short, posts in new media can be considered a narrative form, of an autobiographical kind. They are autobiographical episodes, although perhaps they might be more accurately described as a technology of the self, since they also incorporate reflection, confession and even catharsis (Davis, 2004; Rodríguez-Illera, 2014).

\subsection{Social Media as a Place for Posting Stories}

According to Eagar and Dann (2016), a key aspect of identity is being able to explain the self to ourselves through stories. The selfie is a popular format in the ecology of new media that can be understood as a personal story that helps an individual to present themself. It takes the form of a public visual identity, which involves conscious editing processes and the selection of a photograph, a narrative structure and a wish to share it on social networks. It is not just an aesthetic practice. In fact, the study of Bell (2019) analyzed how adolescents use social networks, with a focus on image-sharing platforms, and found that one important theme was presenting and viewing socially and physically attractive selves, along with maintaining offline relationships, and the importance of visibly quantifiable feedback.

In addition to selfies, whether group ones or individual ones, other popular formats include Instagram stories, which are stories, as the name indicates, but are ephemeral in nature. These vernacular practices, as Burgess (2006) calls them, draw inspiration from the tradition of popular and commercial culture, but they also incorporate everyday and ordinary creative practices, including elements facilitated by smartphones, such as everyday photography and videos (Berry, 2016).

Posts in these participation ecologies emphasize expressive and phenomenological aspects, as a way of sharing experiences and everyday moments (stories) with absent people. Berry (2016) refers to a co-presence in line with these new vernacular and emerging practices; that is to say an individual who posts content takes for granted the existence of a non-present but real audience.

This co-presence in social media posting practices boosts the social or relational aspect through interactions, almost always conditioned by the possibilities of the application in question. For example, the Instagram application enables a narrative approach because it allows the posting of images and videos that integrate the expressivity of mimesis (that which is shown, such as a selfie) and diegesis (what is not shown in the image but rather in an explanatory text that accompanies the image) (Eagar \& Dann, 2016).

\subsection{Personal Digital Storytelling as an Educational Activity}

The everyday posting practices in this new participation ecology imply the possession of certain digital and information competences related to digital and media literacy. These have been studied by authors such as Livingstone (2004), Jenkins (2006) and, in the field of 
education, by Scolari $(2016,2018)$, under the concept of transmedia literacy.

One way of producing personal storytelling forms for educational purposes is the creation of Personal Digital Stories. These short stories (between two and five minutes long) identify and reflect on personal experiences. They are told in a non-professional manner, with a subjective viewpoint and in the first person, integrating audio-visual media (Lambert, 2009; Rodríguez-Illera \& Londoño, 2009). Producing these stories as projects in a formal education setting offers potential in terms of both media literacy and digital literacy, as well as in order to promote processes of reflection and self-knowledge (Rodríguez-Illera, Fuertes, \& Londoño, 2011) and to foster a critical thinking disposition in civic engagement (Chan, 2019). Crafting and telling these stories entails the competences involved in posting content and interaction in the new ecology of media. Digital storytelling is a vehicle for constructivist, self-directed and student-centered pedagogy (Duveskog, Tedre, Islas, \& Sutinen, 2012; Rodríguez-Illera et al., 2011) and can be used for the learning of cross-cutting and specific competences through curriculum-based digital storytelling (Rosales, 2015) and may constitute a pedagogical method for the critical production of personal posts, which in turn could encourage critical reflection on their dissemination and socialization (Mcdougall, Zezulkova, Van Driel, \& Sternadel, 2018; Mirra et al., 2018).

\section{MATERIALS AND METHODS}

\subsection{Ethical Considerations}

Methodological decisions have been taken in accordance with the guidelines of the Code of Good Practice in Research of the University of Barcelona (Universitat de Barcelona, 2010), especially in respect of honesty, rigor, procedures, methods and conflicts of interest. All the participants gave their informed consent in order to collaborate in this research study and the interviewees agreed to the production of an audio recording of their respective interviews. The transcriptions were anonymized in such a way that the records do not contain any personal data that might enable the authors of the answers to be individually identified.

\subsection{Context}

The interviews were conducted between September and October 2018, making the most of the dates of the school calendar in which face-to-face interviews with the students could be conducted without interfering with their studies. In each participating country (Chile, Colombia and Spain), the dates varied slightly. The participants were asked if they wanted to participate, with the added encouragement of the chance to enter a prize draw for some $3 \mathrm{D}$ glasses.

\subsection{Design of the Study}

A qualitative and interpretative method was applied, through which it was possible to carry out an in-depth study of subjective data regarding the use of personal stories. It was designed in line with the proposals of Merriam and Tisdell (2016), and of Twining, Heller, 
Nussbaum, and Tsai (2017), who recommend this method when the goal is not to fragment reality into variables or to reject theories but rather to interpret the participants' reality in an inductive manner using qualitative techniques. This type of method has already been applied in research studies on similar topics (Jager et al., 2017).

\subsection{Sample}

A sample of 21 cases was purposefully selected from among the participants in the project who agreed to be interviewed. The selection criterion was that of maximum variation, according to gender, age and country (Cohen, Manion, \& Morrison, 2007).

The interviewees were 10 women and 11 men. 14 interviewees were from Spain, 4 were from Colombia and 3 were from Chile, and they were between 12 and 20 years old.

\subsection{Technique for Gathering and Analyzing Information}

The research team produced a draft version of the interview script, which was pilot-tested in order to guarantee its applicability. The pilot study was also used to uniformize how the interview was conducted by the four interviewers, to adjust the wording of some questions and to add questions in order to cover more topics of interest. The final script contained 23 open questions and was applied in a semi-structured form. Here are some examples of the questions:

- About use of networks (7 questions)

- Which social networks do you use the most or are you most active in? Which one or ones do you prefer?

- What do you usually do in each of these networks? (posting, etc.)

$-\ldots$

- About type and motivations and perceptions of publications (7 questions)

- What type of content do you like creating and posting in your networks? Give some examples.

- Does how you post depend on the type of content and the specific social network?

- Do you feel that this content can be classified as stories? Why?

- Why do you enjoy creating and posting content in your social networks?

- Is there any content that you would never post? Why? (e.g. violence, offensive content, family-related issues, etc.)

$-\ldots$

- About posting habits (9 questions)

- What elements do you add to your content?

- As regards your friends' posts, do you comment on or share what they post?

- Have you ever deleted a post or certain content after posting it? If so, why did you do it? 
The interviews were transcribed, and their contents were analyzed, classifying and interpreting the answers with the functions of the NVivo program (version 11.4). The process of analysis was carried out in an iterative way until the research team reached an intersubjective agreement on the possible interpretations (Cohen et al., 2007).

The initial analysis categories were restructured into three large macro-categories according to the literature review:

1. Use of networks

2. Content of posts, perceptions and motivating factors

3. Posting habits

The analysis involved a process using both inductive and deductive reasoning through researchers' careful examination of data, having in mind the relevant theory and previous research findings. The procedure was divided into the following steps: transcription, definition of themes as the unit for analysis, development of categories and a coding scheme, test of the coding scheme on a sample text, coding all the text, rechecking the consistency of coding through researchers' discussions, making sense of the categories identified, making inferences and presenting the reconstructions of meanings derived from the data, identifying relationships, uncovering patterns... (Zhang \& Wildemuth, 2017).

\section{RESULTS}

\subsection{Use of Networks}

Most of the young people interviewed began to use social networks when they were between 10 and 13 years old. Instagram is the network on which most participants are most active (17 youths) followed of YouTube (8), Facebook (7), Twitter (4 older participants). Blogs are hardly used (2 participants). Other networks are Snapchat or Tumblr (one person). All participants use WhatsApp, although they do not identify it as a social network.

Each social network serves a different purpose when it comes to posting:

- Instagram is used to look at and follow people, and to post photographs, to make short comments and, in some cases, to write stories.

- YouTube is used for posting videos, although, in many cases, participants' activity is restricted to watching videos posted by others and/or giving likes. Posting videos requires a lot of effort and editing work, according to the participants.

- The participants mainly use the WhatsApp network for chatting and communicating.

- Facebook is used to post some photos, post comments or links, either of personal interest or to their group of acquaintances/friends/family members.

- Twitter is used by participants to keep up to date with news and to give their opinion on topics.

- Blog is used to write and reflect on topics of interest. But it is scarcely used by the participants. 


\subsubsection{Interpretations and Keys for the Integration of These Practices Into the Digital Storytelling Methodology}

Social networking sites used by the participants are the ones that are offered by the big technological companies and the actions and affordances that are used are the ones these platforms allow; that is to say that youths stick to a mainstream predefined pattern of media use. Also, results show a digital gap between the leisure and relational setting, and the academic setting, since no interviewee highlights a specifically educational use of social networks.

The Digital Storytelling methodology can help redirect this situation. It can teach youths to use less-known platforms, which is a necessary action for developing critical consumption literacy skills, less oriented towards media and more oriented towards education, such as the creation of curricular content.

\subsection{Content of the Posts, Motivating Factors and Perceptions}

In this category, the results indicate that the content of posts revolves mainly around the participants themselves, with the focus on what they are doing or thinking when they post their own content: personal photos, family photos, photos of or with friends, of scenery, of travels and of important or everyday moments. These are the most frequent types of content that the study participants say they post. This content mainly seems to emphasize the "Here I am" aspect. They also publish other content related to topics of interest to them or hobbies (poetry, video games, self-help, sport, fashion, etc.), along with thoughts, reflections, opinions, memes, and quotes by other authors that reflect their values. It is curious to observe that young people gain inspiration from other stories or contexts, in other people's posts, for their own posts. One participant said: “(...) I visit the profile of someone with lots of followers. I look for people who I don't know at all, I visit some public profile, I check out their photos and I copy the phrase. But it's not just me doing that. All my friends, everyone does it". However, personal content is scarcer. The participants also post content that is not focused on themselves, such as links to websites of interest.

In respect of the motivating factors for posting content, we have observed several tendencies: showing off (12 youths), for the satisfaction of showing what they do and being seen by others; entertainment (7), reflection (5), information (2). This variety of interests can be observed in the words of the interviewees: "I like people to see what I get up to in my life, for them to follow me, for them to admire me or what I publish"; "I like to be popular"; "There's so much information on [social] networks, you can keep up to date but learn at the same time."; "[Social] networks are a constructive space; you can transmit knowledge, reflections, art".

They see their more personal posts as "slices of life". They say that even a photo in some way explains something about oneself, if it is "meaningful", if from the photo one can deduce their mood, or if it is accompanied by a comment: "We can imagine what this person does, what their life is like, through a photo." Each network is "a life story of its author" as long as the poster does not attempt to embellish reality, but rather, present it as it is. Reflections are also perceived as elements that project the poster's "self" and conscience. 
Furthermore, most of the participants (15) say that they have two profiles on some networks: a public one and a private one. The content they post in each profile is different. In the private profile, the content is more strongly related to emotions and private matters, while the content in the public profile is more neutral.

The participants also impose limits when it comes to posting, showing a high degree of unanimity in ruling out certain posts: those of an intimate nature (romantic relationships, family problems, nudity, etc.); those related to violence, pornography or sexuality; and those related to politics or controversial issues (due to a reluctance to engage in debates or arguments, and to expose themselves to criticism).

With a few exceptions, we observed that the participants generally perceived an evolution in their posts. They have moved on to different topics, they now post more frequently, on more serious issues, and with better-written or higher-quality content. They have become more aware of their activity and look after their image, carefully selecting what they post and, in some cases, avoiding personal issues. They even perceive their evolution as something continuous and look forward to greater evolution in the future, idealizing the posts that they would like to produce. The younger posters would like their posts to have greater quality (nice photos, nice videos), while the older participants aspire to posting more professional content (a book, a blog, their own website, videos on topics of interest to them, scientific knowledge, etc.).

In this respect, some posters delete old posts because they no longer recognize themselves in these posts. Conversely, other posters enjoy tracking their evolution through posts. On the networks with a closed profile, this evolution was less visible, but it was prominent in public networks, where the priority is often to offer an idealized image. On these networks, there is a tendency to show a happy or neutral mood in every element (photos, thoughts, interests, etc.).

They are keen for their posts to be seen above all by people they know, people close to them and some of their followers, (all of whom may coincide with each other in some cases), but not by family.

\subsubsection{Interpretations and Keys for the Integration of These Practices Into the Digital Storytelling Methodology}

The evident predominance of autobiographical posts by the participants, through photos, thoughts, reflections, phrases, quotes and emojis, among other elements, reinforces the idea that social networks are a medium used by young people to shape and project their identity. They themselves are conscious of this projection, perceiving these posts as stories or "slices of life".

This reality presents an opportunity to work on the issue of personal identity by using the methodology of digital storytelling in formal education contexts. Thanks to the reflective process through which digital storytelling is constructed, we can help teenagers and young people to project their real identity rather than the one deemed to fit in socially. Personal digital storytelling can help to foster creativity when it is pedagogically-guided, working on topics such as reflections, dreams or personal wishes, elements or objects of sentimental 
value and learning experiences, integrating compositions that users are used to posting on social networks and contributing to overcoming posting as exhibitionism.

The interviewees reveal in several ways the presence of these two dimensions in their posts (public and private): they have profiles on different networks, some with a more public purpose and others with a more private one; there are aspects that they prefer not to post about, such as romantic relationships, family problems, and controversial issues; and they even prefer their posts not to be seen by certain people, such as family members. In other words, young people are deciding what to tell, who to tell and who not to tell. All of this makes the student consider the issue of privacy: what do I want to tell people about me? Who do I want to see it? How do I want to tell it?

Nevertheless, this transition between the public and private spheres is not an easy one in any context. As the interviewees explain, they prefer to tell stories that are situated in the public sphere, where curricular digital storytelling is found, and, in this sense, it could be well received by young people.

Lastly, the people interviewed feel that the digital stories they post on social networks evolve over time. Storytelling is a means through which we learn from experience by reflecting on it, establishing what it means, transforming it into a symbolic way of expression and recollection. Herein lies the interest of working with the methodology of personal digital storytelling, the strategy of the story in two or more moments, in order to address not only the experiences of the past, or of the present, but also the form in which we project future experiences, especially in life-changing processes or changes of context.

\subsection{Posting Habits}

The interviewees tend to post when they are alone, since this gives them more peace and quiet for editing. Some prefer to think about what they are going to post (to improve the aesthetic quality of the post or to "avoid saying something they will regret later on"); while others post spontaneously, especially on Twitter and WhatsApp. In other social networks, we observe a more unhurried process. We also see that many stories go through an intermediate stage of being classified and stored in readiness for posting when the opportunity presents itself: "I've got plenty filed away. I've got a folder with saved photos. It's really sad... But that's my set-up (...) I've got several folders. One of memes, another one of funny videos, another one which is the photo one, and one of phrases from... books and all the stuff I like".

The main times for posting coincide with the interviewees' free time (outside school/work hours), which reinforces the idea that these young people wait for the right moment in order to calmly prepare their posts.

Nevertheless, if after posting something they decide that they do not like it enough or that it might be "hurtful to someone", half of the interviewees delete or modify the post. Generally speaking, they track their posts, without worrying about the type of comment they receive. Almost all the respondents also track the posts of their friends, offering different types of answers: emojis, comments, hashtags and likes. Some adopt the approach of giving plenty of likes in order not to "frustrate" their friends who post content. 
Most of the young people interviewed tend to add some element to their posts, mainly small texts with still images (photos, memes, etc.), from descriptive or reflective phrases to literary quotes and song lyrics. Half of the interviewees add hashtags to give their posts more potential to go viral. They also add emojis, both for fun and in order to indicate moods and preferences.

Another habit discussed by the participants is the editing of still images using different applications, some of which come preinstalled on smartphones. The purpose of editing, according to the interviewees, is to modify photos for aesthetic reasons. When it comes to editing moving images, posted by only a small number of interviewees, the favored device for editing purposes is the computer.

\subsubsection{Interpretations and Keys for the Integration of These Practices Into the Digital Storytelling Methodology}

Participants follow and comment (in different ways) on each other's posts, while they are also followed by their friends. Beyond the quest for popularity, for social acceptance and for mutual support, in these actions posts are positioned in a communication model that assumes the presence of a sender and a receiver. It is a model that should facilitate critical and self-critical thinking, thus enabling the participants to discover other realities, and other ways of thinking and managing their thoughts and emotions. However, the instantaneousness and superficiality of these actions (many of them through emojis and short texts) suggest that these metacognitive processes do not acquire as much importance as they might.

These processes, though, do play a prominent role in the framework of the methodology of Digital Storytelling, where each student projects their story while, at the same time, forming part of the audience for other stories. The student learns to reflect on the content before publishing it, learns that instantaneousness (misunderstood as naturalness, being "myself") is not appropriate in social networks, even if the deletion of publications is allowed after they have been published.

Therefore, we consider it highly probable that young people, capable of using various applications for content editing, would respond well to incorporating Digital Storytelling into their practice in a formal education setting. Digital competence feeds off both contexts, since different multi-formats and digital tools are used in storytelling.

\section{DISCUSSION AND CONCLUSIONS}

The study has provided an answer to its double aim. Regarding the first objective, we were able to understand youths' narrative practices in digital social networks, with findings that are coincident with other studies in many aspects. Regarding the second objective, based on the experience of young people in social networks, some keys have been obtained to integrate them into formal educational contexts. We discuss these aspects below.

Participants in our study are active consumers of the main social networks and the actions they take in them are constrained by the affordances they provide and by what the 
companies that own them dictate. This is consistent with numerous studies on the use of social media (AIMC, 2021a, 2021b; IAB \& Elogia, 2020); the most frequently used social media are: WhatsApp, YouTube, Instagram, Facebook, Twitter, Spotify and Snapchat. Furthermore, in these networks, they interact, follow others, show moods or tell "stories". The picture that emerges from this situation is that youngsters are consumers of standardized services, and this model is far away from promoting media-literacy among youth, which needs to be empowered in hyper-communicated societies (Gozálvez \& Contreras, 2014).

The methodology of Digital Storytelling can help to replace this apparently independent consumer within the technological market, with an autonomous, responsible and reflective social agent (Drotner \& Livingstone, 2008; Mirra et al., 2018). At the same time, Digital Storytelling can help promote an educational use of media. Studies on Digital Storytelling show that it promotes the acquisition and development of searching, obtaining, processing, exchanging information, communicating and participating skills in collaborative networks through the Internet, which in some way provides the guidelines for reaching the data and information integration level, towards the generation of deep and critical knowledge (Hermann \& Pérez, 2019).

The autobiographical nature of the publications of the participants in this study confirms that social networks are means by which young people project their personal identity, like previous studies have identified (Herreros, 2012; McAdams \& Josselson, 2006; RodríguezIllera, 2014). Social networks act as a mediating element, of their everyday activities, of their forms of body language, of their behavior, and of their peer relations. The methodology of Digital Storytelling is presented as an opportunity to channel this situation, taking into consideration authors who argue that identity is constructed through the stories we tell about ourselves (Davis, 2004; Lambert, 2009; Lundby, 2008; Ohler, 2008).

Exhibitionist reasons for publishing fall into the category of the so-called spectacle society (Abercrombie \& Longhurst, 1998), in which any item can be immortalized and shared with a diffused audience, always offering the best image of oneself in search of social approval, showing, once again, a user that is little committed to reflective and empowered media participation. This gap between being and pretending can distort the development of identity and can be overcome by learning about digital narratives in formal contexts.

The posts of the participants show a double dimension (public and private), although they prefer to tell stories that are situated in the public sphere, a fact also highlighted in studies by other authors (Herreros, 2012). These results contrast with the argument that social networks are spaces where the private, the intimate and the public all merge together, since technology forms part of our world which is always shared (Ridder \& Van Bauwel, 2015; Sánchez et al., 2015). Similarly, they impose limits when it comes to posting topics about intimate, controversial, or harmful topics.

The preference for the public sphere can be harnessed by Digital Storytelling as curriculum-based storytelling, which mainly concentrates on the public sphere, enables us to work on both specific and cross-cutting competences (Rosales, 2015).

The people interviewed feel that the digital stories they post on social networks evolve over time, both in terms of their form and their content, and that the construction of 
one's personal identity is a lifelong process (Mcadams, 1996). As time goes by, we codify and store new experiences that interfere with our capacity to recall and perceive previous ones (Schater, 2003). Storytelling is a means through which we learn from experience by reflecting on it, establishing what it means, transforming it into a symbolic way of expression and recall.

Young people show posting habits that emphasize spontaneity in the use of various elements in posts, editing and modification, as has been identified in previous research (RuizCorbella \& Juanas, 2013). In these publication habits, they use different applications, thereby demonstrating digital skills, as other studies affirm (Rebollo, García, \& Mayor, 2015). One of the main habits of young people on social media is to follow the publications of others while they are also followed by their friends, a habit that is consolidated and reinforced through comments, as other studies have also shown (Quintana, 2016).

These processes do play a prominent role in the framework of the methodology of Digital Storytelling, where each student projects their story while at the same time forming part of the audience for others' stories. It thus fosters reflection on the "self", while strengthening the construction of personal identity as a collective process (McAdams \& Josselson, 2006).

\subsection{Implications for the Field of Study}

The type of practices of young people in social networks, the motivations for using them, how they perceive them and how they use them have been verified, from a comprehensive and not only a descriptive perspective. Understanding these practices has provided "clues" for teachers and researchers for their integration into formal contexts.

Young people already construct stories on social networks, in a broad sense of the concept of storytelling, and they enjoy doing so for different reasons. However, this process could be further strengthened in a formal education setting, attaching greater importance to reflection and helping students to construct digital stories as new forms of learning, reflection and social participation as citizens.

\subsection{Recommendations for Educational Practice}

In the educational field, we recommend promoting a new learning ecology using technology (Barron, 2006; Rodríguez-Illera, 2014), with an emphasis on students in their role as receivers and critical producers of digital content (autobiographical, curricular, etc).

Specifically, making an educational use of digital narratives can help young people improve their own storytelling practices on the basis of reflecting on their own self, on their own learning processes, on the discovery of other ways of thinking, on the acceptance of others, on criticism and self-criticism, and on responsible social participation. The results have also helped the research team to create proposals aimed at educational praxis. Digital storytelling workshops have been held with secondary school students, who welcomed the resource enthusiastically. Additionally, a self-training kit has been designed (Galván \& Martínez-Fernández, 2019), aimed at guiding teachers in the use of digital storytelling with their students. 


\subsection{Limitations and Further Research}

This study also has limitations, such as a small sample that prevents generalization of the results and the difficulty of comparing our results with other studies due to the scarcity of interpretive research in this area. These are limitations that offer new opportunities for future research. Thus, it may be necessary to directly study the perceptions of young people on educational methodologies such as digital storytelling, and to carry out an intervention with them in order to empirically support our interpretations in the present study. It would also be interesting to conduct a study to understand and interpret the meanings that young people give to these everyday publishing practices within the framework of their different learning experiences in life, or to identify factors and variables associated with the successful integration, acceptance and expansion of these practices in interdependent learning contexts.

\section{ACKNOWLEDGEMENTS}

Funded by: Ministry of Economy and Competitiveness, Spain

Funder Identifier: http://dx.doi.org/10.13039/501100003329

Award: EDU2016-76726-P

Funded by: European Regional Development Fund, Europe

Funder Identifier: http://dx.doi.org/10.13039/501100008530

Award: EDU2016-76726-P

\section{ADDITIONAL INFORMATION AND DECLARATIONS}

The authors declare that there is no conflict of interest.

\section{REFERENCES}

Abercrombie, N., \& Longhurst, B. (1998). Audiences. SAGE Publications.

Asociación para la Investigación de Medios de Comunicación. AIMC. (2021a). 23º Navegantes en la Red - Encuesta AIMC a usuarios de Internet. AIMC-Asociación para la Investigación de Medios de Comunicación. Retrieved from http://download.aimc.es/aimc/cc8ke5T/ macro2020/\#page $=1$

Asociación para la Investigación de Medios de Comunicación. AIMC. (2021b). Infografía resumen $23^{\circ}$ Navegantes en la Red. Retrieved from https://www.aimc.es/otros-estudios-trabajos/ navegantes-la-red/infografia-resumen-23o-navegantes-la-red/

Bai, Q., Dan, Q., Mu, Z., \& Yang, M. (2019). A Systematic Review of Emoji: Current Research and Future Perspectives. Frontiers in psychology, 10, 2221-2221. https://doi.org/10.3389/ fpsyg.2019.02221

Barron, B. (2006). Interest and self-sustained learning as catalysts of development: A learning ecology perspective. Human development, 49(4), 193-224.

Bell, B. T. (2019). You take fifty photos, delete forty nine and use one": A qualitative study of adolescent image-sharing practices on social media. International Journal of Child-Computer Interaction, 20, 64-71. https://doi.org/10.1016/j.ijcci.2019.03.002 
Berry, M. (2016). Out in the open: locating new vernacular practices with smartphone cameras. Studies in Australasian Cinema, 10(1), 53-64. https://doi.org/10.1080/17503175.2015 .1084173

Brandtzaeg, P. B., \& Chaparro-Domínguez, M. A. (2020). From Youthful Experimentation to Professional Identity: Understanding Identity Transitions in Social Media. YOUNG, 28(2), 157-174. https://doi.org/10.1177/1103308819834386

Bruner, J. (2006). Actos de significado. Más allá de la revolución cognitiva. Alianza.

Bruns, A. (2008). Blogs, Wikipedia, Second Life, and beyond: From Production to Produsage. Peter Lang.

Burgess, J. E. (2006). Hearing ordinary voices: Cultural studies, vernacular creativity and digital storytelling. Continuum: Journal of Media \& Cultural Studies, 20(2), 201-214. https://doi.org/ $10.1080 / 10304310600641737$

Chan, C. (2019). Using digital storytelling to facilitate critical thinking disposition in youth civic engagement: A randomized control trial. Children and Youth Services Review, 107. https:// doi.org/10.1016/j.childyouth.2019.104522

Cohen, L., Manion, L., \& Morrison, K. (2007). Research methods in education (6th ed.). Routledge. https://doi.org/10.4324/9780203029053

Davis, A. (2004). Co-authoring identity. Digital storytelling in an urban middle school. THEN: Technology, Humanities, Education and Narrative, 1, 1-12.

Dennen, V. P., Choi, H., \& Word, K. (2020). Social media, teenagers, and the school context: a scoping review of research in education and related fields. Educational Technology Research and Development, 68, 1635-1658. https://doi.org/10.1007/s11423-020-09796-z

Drotner, K., \& Livingstone, S. (2008). The International Handbook of Children, Media and Culture. Sage.

Duveskog, M., Tedre, M., Islas, C., \& Sutinen, E. (2012). Life Planning by Digital Storytelling in a Primary School in Rural Tanzania. Educational Technology \& Society, 15(4), 225-237.

Eagar, T., \& Dann, S. (2016). Capturing and Analyzing Social Media Composite Content: The Instagram Selfie. Consumer Culture Theory, 18, 245-265. https://doi.org/10.1108/S0885 $-211120160000018016$

Egan, K. (1986). Teaching as story telling. Routledge.

Galván, C., \& Martínez-Fernández, A. (2019, November). Un kit para el autoaprendizaje de relatos digitales. Seminario de Educación Virtual: El presente y el futuro de los relatos digitales personales. Barcelona, Spain.

Galvin, S., \& Greenhow, C. (2020). Writing on Social Media: a Review of Research in the High School Classroom. TechTrends, 64, 57-69. https://doi.org/10.1007/s11528-019-00428-9

Gozálvez, V., \& Contreras, P. (2014). Empoderar a la ciudadanía mediática desde la educomunicación. Comunicar, 42, 129-136. http://dx.doi.org/10.3916/C42-2014-12

Gregori-Signes, C., \& Corachán, A. M. B. (2014). Appraising Digital Storytelling across Educational Contexts. Publicacions de la Universitat de València.

Guerrero, M., Masanet, M. J., \& Scolari, C. A. (2018). Toward a typology of young produsers: Teenagers' transmedia skills, media production, and narrative and aesthetic appreciation. New Media \& Society, 21(2), 336-353. https://doi.org/10.1177/1461444818796470

Hermann, A., \& Pérez, A. (2019). Narrativas digitales, relatos digitales y narrativas transmedia: revisión sistemática de literatura en educación en el contexto iberoamericano. Revista Espacios, 40(41), 1-13.

Herreros, M. (2012). El uso educativo de los relatos digitales personales como herramienta para pensar el Yo [The educative use of personal digital storytelling as tool for thinking on my-Self. Digital Education Review, 22, 68-79. Retrieved from http://revistes.ub.edu/index.php/der/ 
article/view/11296/pdf

Herreros, M. (2019). La auto-representación del Yo (Self) a través del Digital Storytelling: el digital Storytelling como herramienta para trabajar la identidad personal (Self) en bachillerato (Doctoral dissertation, Universitat de Barcelona, Barcelona). Retrieved from http://hdl.handle.net/ $10803 / 668725$

IAB \& Elogia. (2020). Estudio Anual de Redes Sociales 2020. Retrieved from https://iabspain.es/ estudio/estudio-redes-sociales-2020/

Jager, D., Fogarty, A., Tewson, A., Lenette, A., Boydell, C., \& M, K. (2017). Digital storytelling in research: A systematic review. The Qualitative Report, 22(10), 2548-2582. https://doi.org/ $10.46743 / 2160-3715 / 2017.2970$

Jenkins, H. (2006). Convergence culture: where old and new media collide. New York University Press.

Jenkins, H., Ito, M., \& Boyd, D. (2015). Participatory cultures in a networked era: a conversation on youth, learning, commerce and politics. Polity Press.

Jenkins, H., Purushotma, R., Weigel, M., Clinton, K., \& Robison, A. J. (2009). Confronting the Challenges of Participatory Culture. Media Education for the 21st Century. The MIT Press. https://doi.org/10.7551/mitpress/8435.001.0001

Lambert, J. (2009). Digital Storytelling. Digital Diner Press.

Lévi-Strauss, C. (1966). The savage mind. Chicago University Press.

Livingstone, S. (2004). Media Literacy and the Challenge of New Information and Communication Technologies. Commmunication Review, 7, 36-50. https://doi.org/10.1080/ 10714420490280152

Lundby, K. (2008). Digital Storytelling, Mediatized Stories. Self-representations in New Media. Peter Lang Publishing.

Martínez, J. B., \& Hernández, E. (2017). Revisión crítica de los informes sobre el uso de las nuevas tecnologías y sus efectos socioeducativos. Revista de Educación mediática y TIC, 6(2), 317335. https://doi.org/10.21071/edmetic.v6i2.5319

Mcadams, D. P. (1996). Personality, Modernity, and the Storied Self: A Contemporary Framework for Studying Persons. Psychological Inquiry, 7(4), 295-321. https://doi.org/10.1207/ s15327965pli0704_1

McAdams, D. P., \& Josselson, R. (2006). Identity And Story: Creating Self in Narrative (A. Lieblich, Ed.). American Psychological Association. https://doi.org/10.1037/11414-000

Mcdougall, J., Zezulkova, M., Van Driel, B., \& Sternadel, D. (2018). Teaching media literacy in Europe: evidence of effective school practices in primary and secondary education. Publications Office of the European Union.

Merriam, S. B., \& Tisdell, E. H. (2016). Qualitative Research. A Guide to Design and Implementation (4th ed.). Jossey-Bass.

Mirra, N., Morrell, E., \& Filipiak, D. (2018). From Digital Consumption to Digital Invention: Toward a New Critical Theory and Practice of Multiliteracies. Theory into Practice, 57(1), 12-19. https://doi.org/10.1080/00405841.2017.1390336

Ohler, J. (2008). Digital storytelling in the classroom: new media pathways to literacy, learning, and creativity. Corwin Press, cop.

Quintana, G. M. (2016). Motivos para el uso de Instagram en adolescentes (Unpublished doctoral dissertation). Universidad de Cantabria, Santander.

Rebollo, A., García, R., \& Mayor, V. (2015). Las competencias digitales en las redes sociales como indicador de las nuevas alfabetizaciones . CINAIC, Congreso Internacional sobre Aprendizaje, Innovación y Competitividad, Madrid, Spain.

Ricoeur, P. (1996). Sí mismo como otro. Siglo XXI. 
Ridder, S. D., \& Van Bauwel, S. (2015). The discursive construction of gay teenagers in times of mediatization: youth's reflections on intimate storytelling, queer shame and realness in popular social media places. Journal of Youth Studies, 18(6), 777-793. https://doi.org/10.1080/ 13676261.2014 .992306

Rodríguez-Illera, J. L. (2014). Personal storytelling in the digital society. In C. Gregori-Signes \& A. B. Corachán (Eds.), Appraising Digital Storytelling across Educational Contexts (pp. 41-58). Publicacions de la Universitat de València.

Rodríguez-Illera, J. L., Fuertes, M., \& Londoño, G. (2011). Histoires numériques avec des adultes. In I. Loiodice, P. Plas, \& N. Rajadell (Eds.), Université et Formation tout au long de la vie. L'Harmattan.

Rodríguez-Illera, J. L., \& Londoño, M. G. (2009). Los relatos digitales y su interés educativo. Educação, Formação \& Tecnologias, 2(1), 5-18.

Rosales, S. E. (2015). Uso del relato digital en la educación. Influencia en las habilidades del alumnado y el profesorado (Unpublished doctoral dissertation). Universidad de Alicante, Alicante.

Ruiz-Corbella, M., \& Juanas, A. D. (2013). Redes sociales, identidad y adolescencia. Nuevos retos educativos para la familia. Estudios sobre Educación, 25, 95-113.

Sánchez, L., Crespo, G., Aguilar, R., Bueno, F., Aleixandre, R., \& Valderrama, J. (2015). Los adolescentes y las tecnologías de la información y la comunicación. Unitat de Prevenció Comunitaria de Conductes Adictivas del Ayuntamiento de Valencia. Retrieved from http://digital.csic.es/ bitstream/10261/132633/1/TICPadres.pdf

Schater, D. (1999). Sobre el tiempo y la autobiografía. En busca de la memoria. El cerebro, la mente y el pasado. Ediciones B.

Schater, D. (2003). Los siete pecados de la memoria. Ariel.

Scolari, C. A. (2016). Estrategias de aprendizaje informal y competencias mediáticas en la nueva ecología de la comunicación. Transmedia Literacy. Informal Learning Strategies and Media Skills in the New Ecology of Communication, 103, 13-23.

Scolari, C. A. (2018). Teens, media and collaborative cultures: exploiting teens' transmedia skills in the classroom. Universitat Pompeu Fabra.

Shah, R., \& Tewari, R. (2021). Mapping Emoji Usage Among Youth. Journal of Creative Communications, 16(1), 113-125. https://doi.org/10.1177/0973258620982541

Toffler, A. (1980). The Third Wave. Bantam Books.

Twining, P., Heller, R. S., Nussbaum, M., \& Tsai, C. C. (2017). Some guidance on conducting and reporting qualitative studies. Computers \& Education, 106, 1-9. https://doi.org/10.1016/ j.compedu.2016.12.002

Universitat de Barcelona. (2010). Code of Good Research Practices. Retrieved from http://hdl.handle .net/2445/28544

Vanwynsberghe, H., \& Verdegem, P. (2013). Integrating Social Media in Education. CLCWeb: Comparative Literature and Culture, 15(3). https://doi.org/10.7771/1481-4374.2247

Winocur, R. (2007). Nuevas tecnologías y usuarios. La apropiación de las TIC en la vida cotidiana. TELOS, 73, 109-117.

Zhang, Y., \& Wildemuth, B. M. (2017). Qualitative Analysis of Content. Applications of Social Research Methods to Questions in Information and Library Science (2nd ed., pp. 318-329). Libraries Unlimited. 